DOI: $10.5585 /$ cpg.v17n2.8429

\title{
IDENTIDADE QUILOMBOLA E EDUCAÇÃO ESCOLAR \\ QUILOMBOLA: CONTRIBUIÇÕES A PARTIR DA EXPERIÊNCIA \\ DE UM QUILOMBO
}

QUILOMBOLA IDENTITY AND QUILOMBOLA SCHOOL EDUCTION:

CONTRIBUTIONS FROM THE EXPERIENCE OF A QUILOMBO

\begin{abstract}
Sandra Nivia Soares de Oliveira
Doutora em educação pela Universidade Federal da Bahia. Professora adjunta da Universidade Estadual de Feira de Santana. Bahia - BA - Brasil. sandraniviasoares@gmail.com
\end{abstract}

\begin{abstract}
Resumo: Neste trabalho, toma-se o processo de construção da identidade do quilombo de Mangal e Barro Vermelho, situado no Oeste da Bahia-Brasil, compreendendo que sua história e seu processo de construção da identidade podem contribuir para a formação de professores, no debate sobre a educação escolar quilombola e na efetivação de suas diretrizes, entendendo quilombo como uma categoria dinâmica que se atualiza no tempo, ressaltando os diversos caminhos para a construção da identidade quilombola e a necessidade de atentar a essa questão nas discussões sobre a educação de quilombolas. Este trabalho toma como referência os dados de pesquisa de mestrado, ancorada nos aportes teórico-metodológicos da história oral, e a experiência da autora na formação de professores.
\end{abstract}

Palavras-chave: Educação Escolar Quilombola. Quilombo. Identidade Negra.

Abstract: In this work, the process of constructing the identity of the quilombo of Mangal and Barro Vermelho, situated in the west of Bahia-Brazil, is carried out, understanding that its history and its identity-building process can contribute to the formative process of teachers in the debate about quilombola school education and the implementation of its guidelines, understanding quilombo as a dynamic category that is updated in time, highlighting the different

Cadernos de Pós-graduação, São Paulo, v. 17, n. 2, p. 35-54, jul./dez. 2018. 
paths for the construction of quilombola identity and the need to address this issue in the discussions about quilombola education. This work takes as reference the data of masters research anchored in the theoretical-methodological contributions of oral history and the author's experience in teacher education.

Key-Words: Quilombola School Education. Quilombo. Black Identity.

\section{Introdução}

articipando como formadora do Curso de Formação de Professores Edu-
cação Escolar Quilombola (FORMEEQ) - uma parceria entre a Universidade Federal do Recôncavo Baiano e a Secretaria de Educação do Município de Feira de Santana, senti necessidade de revisitar minha dissertação de mestrado De Mangazeiros a Quilombolas: Terra Educação e Identidade em Mangal e Barro Vermelho, defendida no ano de 2006, na Universidade do Estado da Bahia (UNEB), por conta dos questionamentos feitos por dois cursistas acerca da concepção de quilombo e da identidade quilombola de/em algumas comunidades.

No trabalho realizado no FORMEEQ, percebia-se, entre os professores, o conflito que se instalou após o reconhecimento e titulação de algumas destas comunidades. Professores que trabalhavam na comunidade, há anos, de repente não sabiam o que ensinar e nem como ensinar aos mesmos alunos. Uma fala em especial chamou a minha atenção: "professora, agora que eles viraram quilombolas, estou confusa." Creio que este conflito não seja de uma professora em particular; por esta razão, me senti desafiada a construir um texto que possa auxiliar esses professores e professoras na compreensão do que seja quilombo e do que autoriza uma comunidade a ser reconhecida como quilombola e assim se identificar. As reflexões que aqui me proponho a fazer estão ancoradas na minha dissertação de mestrado e nas Diretrizes Curriculares Nacionais para a Educação Escolar Quilombola na educação Básica (BRASIL, 2012), que coloca mais um desafio aos sistemas educacionais, às escolas, aos professores, aos alunos e às comunidades quilombolas: pensar e construir uma escola que dê conta de atender as

Cadernos de Pós-graduação, São Paulo, v. 17, n. 2, p. 35-54, jul./dez. 2018. 
especificidades das comunidades quilombolas, evidenciadas a partir do reconhecimento legal dessas comunidades.

Desde o reconhecimento, apresentado no Ato das Disposições Constitucionais Transitórias, em seu Artigo 68 -, do direito à terra e à titulação aos herdeiros da resistência ao regime de escravidão no Brasil (BRASIL, 1988), o conceito de quilombo precisou ser ressignificado para que pudesse atender as especificidades das comunidades negras que reivindicam as terras onde vivem secularmente, tomando a identidade quilombola como estratégia de afirmação da ancestralidade e de visibilização de uma história intencionalmente ocultada por razões políticas, sociais, econômicas e culturais.

Neste trabalho, toma-se o processo de construção de identidade da comunidade negra quilombola de Mangal e Barro Vermelho, no Oeste da Bahia, como referência para refletir sobre o conceito de quilombo, ampliando a compreensão sobre essas comunidades, contribuindo para a desconstrução de preconceitos e favorecendo a convivência respeitosa entre as diversas culturas.

\section{Algumas considerações sobre quilombo e quilombo contemporâneo}

Tradicionalmente, quilombo designa esconderijo de negro fugido. De acordo com o parágrafo terceiro do regimento de 1724, por quilombo se devia entender “[...] toda habitação de negros fugidos que passe de cinco em parte despovoada ainda que não tenham ranchos levantados nem nela se achem pilões" (apud, LARA, 1996, p.43). O regimento de 1733, aprovado pela Câmara de São Paulo, apresenta outra definição de quilombo, sendo este "[...] o ajuntamento de mais de quatro escravos vindos em matos para viver neles e fazerem roubos e homicídios [...]" (apud, LARA, 1996, p.44). 
Observa-se que, no contexto da escravidão, o conceito de quilombo variou de acordo com a realidade de cada lugar, tendo como ponto de intersecção a fuga do regime, indicando o movimento que fez o conceito para se adequar às realidades e experiências naquele contexto, "tratando-se de uma definição operacional diretamente ligada ao estabelecimento dos salários do capitão-do-mato, mas que é, sobretudo, uma definição política" (LARA, 1996, p.97).

A Constituição Federal de 1988, com a conquista do Artigo 68, dos Atos das Disposições Constitucionais Transitórias - no qual afirma que aos remanescentes das comunidades dos quilombos que estejam ocupando suas terras, é reconhecida a propriedade definitiva, devendo o Estado emitir-lhes os títulos respectivos -, revela a necessidade de repensar o conceito de quilombo a partir da diversidade de comunidades negras.

Com essa preocupação a Associação Brasileira de Antropologia (ABA) atualizou o conceito de quilombo afirmando que,

Contemporaneamente, portanto, o termo quilombo não se refere a resíduos ou resquícios arqueológicos de ocupação temporal ou de comprovação biológica. Também não se trata de grupos isolados ou de uma população estritamente homogênea. Da mesma forma nem sempre foram constituídos a partir de movimentos insurrecionais ou rebelados, mas, sobretudo, consistem em grupos que desenvolveram práticas cotidianas de resistência na manutenção e reprodução de seus modos de vida característicos na consolidação de um território próprio. (O’DWYER, 1995, apud MOURA, G., 1999, p. 102 103).

No bojo da luta do Movimento Negro pela reparação social, especialmente a partir da promulgação da constituição de 1988, quilombo, uma categoria coletiva (VÉRAN, 1999 p.199) que estava no passado, é retomada, e seu conceito ganha novo sentido. O conceito de quilombo é, nesse momento, repensado e reconstruído politica- 
mente no jogo do poder, abrindo possibilidades para as populações negras rurais, historicamente marginalizadas, do direito ao reconhecimento de uma ancestralidade que lhes garantirão benefícios políticos e materiais.

Abordar a ressemantização do conceito de quilombo é importante porque só a partir daí é possível pensar em Mangal como quilombo, visto que as comunidades negras de Mangal e Barro Vermelho não aparecem na narrativa de seus moradores, nem em qualquer outro documento, como tendo sido quilombo a partir dos conceitos apresentados pela historiografia tradicional - como lugar de negro fugido. Mangal e Barro Vermelho têm todas as características daquilo que podemos denominar de Terra de Santo $^{1}$, como se pode evidenciar no depoimento do senhor Santos, I (2005) : " [...] a terra pá Santa quem deu foi uma mulher que tinha aqui que era de minha família [...].”

Diante desse cenário, no estudo dessa comunidade, a memória a ser valorizada não é se o grupo em questão tem ou não alguma relação com as formações que se encaixam na definição tradicional de quilombos, que tem em Palmares sua principal referência, outros elementos precisam ser considerados. Quilombo, nessa perspectiva, é o lugar da resistência, e resistência não se dá de uma mesma forma em territórios e contextos diferentes, muito menos entre sujeitos diferentes. Não reconhecer essa complexidade é desconsiderar a dialética das relações entre os sujeitos e seus contextos e entre si.

Fora dessa perspectiva, Mangal jamais poderia ser reconhecido como quilombo, pois mesmo o termo quilombola era desconhecido na Comunidade, como podemos observar na fala de Pereira (2005), um dos moradores: “[...] o senhor desculpa as minhas expressão, a minha ingnorança, o que... que é quilombo? Porque o quilombo que, que... que eu entendo é quilometrage, é midição”. A fala de Pereira(2005), diante do repre- 

CONTRIBUIÇÕES A PARTIR DA EXPERIÊNCIA DE UM QUILOMBO

sentante do INCRA, em 1997, deixa claro que nem sempre se foi quilombola em Mangal/Barro Vermelho e, portanto, Mangal nem sempre foi quilombo a partir de uma concepção tradicional.

O modo como Mangal garantiu a sobrevivência dos elementos destacados por eles como fundantes na construção da identidade tem como cenário um pedaço de terra às margens do Rio São Francisco, que é o lugar onde se desenvolveram mitos, ritos, fazeres e saberes que, para eles, dão suporte à identidade do grupo ou à identidade de cada um, fazendo dele quilombo, compreendido como lugar de resistência e de transgressão.

Dessa forma, discutir o que é quilombo e identidade quilombola é uma necessidade política e pedagógica, especialmente a partir da aprovação das Diretrizes Curriculares Nacionais para a Educação Escolar Quilombola na Educação Básica (BRASIL, 2012), que tem provocado movimentos políticos e pedagógicos no interior dessas instituições escolares, muitas vezes por desconhecimento de seu significado histórico e de sua amplitude. Nesse sentido, contar a história de Mangal e Barro Vermelho contribui para fortalecer a compreensão do processo histórico de identificação e reconhecimento das diversas comunidades quilombolas presentes em nosso território.

Ressalte-se a necessidade de se tomar o cuidado para não pensar em quilombo no singular, o que equivale a dizer que, ainda que as histórias e modos de viver da comunidade de Mangal e Barro Vermelho se aproximem da história de outras comunidades quilombolas, cada história é uma história particular. Mas é exatamente porque, embora diversas, estas comunidades estão ligadas entre si pelo passado da escravidão, que determinou as condições atuais de suas existências, que a história do Mangal tornase uma referência para outras realidades.

Mangal reivindicou a identidade quilombola no bojo da luta pela terra, a qual, posteriormente, se desdobrou num processo de retomada de sua história e identidade. 
Foi assim que a comunidade em pouco mais de dois anos passou de mangazeira à quilombola ao ser reconhecida como "remanescente" de quilombo em 1998, inclusive pela consciência de que não se tornariam quilombolas se não fossem mangazeiros.

\section{Antes, "mangazeiros", negros feiticeiros; hoje, quilombolas: ressignificando a identidade}

O povo do Mangal está arraigado naquelas terras, segundo a tradição oral, às margens do Rio São Francisco, no Município de Sítio do Mato-Estado da Bahia, desde o século XVIII, onde construíram a experiência histórica de se reproduzirem, de produzirem as condições de sua existência e de reproduzirem a cultura de seus ancestrais, nem sempre do mesmo jeito, mas no jogo da vivência e sobrevivência, conservando e/ou reformulando significados. Segundo os relatos orais, a comunidade surge a partir da escravaria de certo Capitão João, que teria se apaixonado por uma escrava e que, a pedido dela, teria doado a terra a Nossa Senhora do Rosário. Desde então, os negros da fazenda passaram a morar no Mangal, lugar onde se soltava o gado. Na negociação com seu entorno, durante muito tempo, a comunidade - de origem escrava e adepta a práticas religiosas de matriz africana -, negou sua crença, tomando a Nossa Senhora do Rosário como padroeira. Ser Mangazeiro era ser reconhecido pelo entorno como negros feiticeiros.

Muitas histórias à beira do Rio São Francisco foram construídas em torno do que chamo de hetero-identidade, pois eles eram reconhecidos pelo outro como mangazeiros, mas não se auto-reconheciam como tal. Nos anos 1990, a possibilidade de perda da terra, que lhes pertenciam legitimamente, mas não legalmente, possibilitou a esses negros e negras a (re)conhecerem suas histórias quando, mais uma vez, um outro 

CONTRIBUIÇÕES A PARTIR DA EXPERIÊNCIA DE UM QUILOMBO

lhes dizem que são, agora, quilombolas. A partir de então, a comunidade faz um movimento de retomada de suas histórias e, para se tornarem quilombolas, retomam e ressiginificam a identidade mangazeira. Assim, Mangazeiros, que até então não sabiam o que era quilombo, tornam-se quilombolas.

Um pressuposto que permeia a concepção de identidade nesta discussão é que esta é construída coletivamente, posto que é "um processo de duas vias em operação tanto no indivíduo quanto no grupo" (GIRAUDO, 1997, p.12). Embora a internalização dos elementos constituintes da identidade passe, necessariamente, por um processo de individuação, seria impossível a construção da identidade sem as marcas de uma experiência coletiva que religue o passado ao presente, principalmente porque,

Toda e qualquer identidade é construída. A principal questão, na verdade, diz respeito a, como, a partir de quê, por quem e para que isso acontece. A construção de identidades vale-se da matéria prima fornecida pela história, geografia, biologia, instituições produtivas e reprodutivas, pela memória coletiva e por fantasias pessoais, pelo aparato de poder e revelações de cunho religioso. (CASTELLS, 1999, p. 23).

A reflexão acerca da relação da Comunidade com a experiência da escravidão e da discriminação, a lida na terra e com a terra, bem como a luta por sua conquista, além de seus ritos e festejos, são os recortes priorizados na análise desse tecido.

O medo de falar da escravidão como forma de evitar com que esta se repita e o silêncio sobre a questão que desemboca na ignorância das gerações mais jovens sobre o assunto são evidências do quanto este tema é relevante para se pensar a identidade na comunidade. Mesmo porque, embora institucionalmente a escravidão tenha sido abolida no Brasil, em Mangal, em 2006, era atual o medo desta, como demonstra Pereira (2005, informação oral): “[...] fico procupado com essa geração, porque se num souber fazer..., a escravidão, ela pode tornar a vim; e, se ela vim agora, ela vem mais feia, porque 
ela num cabou, civilizou.” Uma referência explícita às condições de desigualdades, nas quais estão submetidos os negros.

A origem escrava da comunidade e, por conseguinte, sua afrodescendência, discriminada pela sociedade local, rendeu aos moradores a "pecha" "mangazeiro". Foi o entorno que assim os denominou de forma preconceituosa. Ser "mangazeiro", significava ser negro feiticeiro. A forma pejorativa como eram tratados pela vizinhança, durante muito tempo, fez com que os "mangazeiros" negassem sua origem. Vários relatos de moradores dão conta da visão que tinha a vizinhança em relação a eles, a exemplo do relato de Pereira (2005, informação oral), que diz que "[...] naquele tempo era a pobreza, nué? Era a pobreza, era uns negos, beiçudos, eram preguiçosos, era feiticeiro, entendeu? Só vinha aqui quem tinha negoço.”

Além da narrativa acima, o relato de Souza M.(2005, informação oral), a seguir, também evidencia o quanto a relação de Mangal com o seu entorno era marcada pela discriminação, embora tivesse que manter com este atividades comerciais que assegurassem a sobrevivência do grupo. "Porque até 1998 pa trás, nenhum rapaz do Mangal, aqui, chegava em Gamelêra, namorava uma moça. Chegava em Paratinga, namorava.”

A rejeição da vizinhança favoreceu o casamento endogâmico na Comunidade, o que contribuiu para que eles vivessem voltados para as relações internas e fortalecessem laços de solidariedade importantes na história deles como elemento de resistência. Por essa razão, a relação destes moradores com seu entorno era bastante restrita. Até mesmo o poder público desconsiderava a existência da Comunidade. "Eles vivia aqui isoladamente, parecia uns vereador aqui de quatro em quatro ano, pra pegar os voto. $\mathrm{E}$ eles: "voto, voto, voto, voto", entendeu? E aí, o galante sumia", relata Pereira (2005, informação oral). É nesse contexto conflituoso e marcado por negociações com seu entorno que os mangazeiros construíram a sua (s) existência (s) e, por conseguinte, sua(s) identidade(s). 
Nesse sentido, a memória dos mais velhos teve papel relevante na transmissão e ressignificação de conhecimentos, saberes e valores que fizeram da Comunidade única, mesmo partilhando características gerais com outras comunidades negras rurais. A singularidade dela é construída na atualização da experiência que impossibilita a reprodução fiel do vivido que ganha sentido único no contexto em que se insere, posto que "atemporal, no mínimo, pode levar a cristalização de valores absolutamente extemporâneos em relação às características e demandas da contemporaneidade" (MATTOS, 2003, p.30).

O processo de construção das identidades nasce de situações reais de vida. No caso específico de Mangal, a luta pela conquista da terra é a luta de um grupo que vivenciou, por um longo tempo, uma história marcada pelo preconceito e pela possibilidade de expulsão de seu território, solo de origem onde estão enraizadas memórias e histórias relevantes para a Comunidade.

A terra para a comunidade de Mangal é território para além de espaço físico, é também espaço político no qual são implementadas ações e negociações que possibilitam ao grupo a manutenção de valores comunitários que, certamente, garantiram a sobrevivência do grupo em meio a todos os conflitos vividos. Nesse contexto, "O território aparece assim como um dado necessário à formação da identidade grupal/individual, ao reconhecimento de si por outros" (SODRÉ, 1999, p.15).

O modo peculiar com que a Comunidade ocupa a terra é um elemento de identificação e diferenciação desse espaço. Por ocasião do reconhecimento, o Instituto Nacional de Colonização e Reforma Agrária (INCRA) propunha que a comunidade em questão se organizasse de acordo com o padrão considerado para todos os assentamentos em área de reforma agrária. Nesse modelo, a divisão do território se daria por lotes individuais onde o cultivo da terra e a decisão do que plantar seriam uma prerrogativa individual. Tal proposta foi desconsiderada pelo grupo, que se recusou a 
lotear a terra nos moldes apresentados pelo INCRA. As primeiras habitações foram construídas às margens do Rio, próximas umas das outras. Eis duas referências importantes na observação do morar em Mangal.

O depoimento de Gomes (2005, informação oral) é bastante ilustrativo do que vem a ser o modo como a Comunidade se relaciona com o seu território: "a coletividade. Porque se não tivesse, nós tava igual os outros assentamentos. Cada um com seu pedacinho, cada um olhando pro seu umbigo. Nada de olhar pra ninguém”.

Da terra eles tiram o sustento desde os tempos em que a memória coletiva aponta como o marco da origem da Comunidade. Segundo essas memórias, o marco delimitador do tempo originário daquele povo em suas terras é o tempo do cativeiro, tempo do Capitão João. Desde aquela época, a prática por meio da qual esses indivíduos viabilizavam seu sustento era a lida na terra. Souza, C.(2005, informação oral) relata como os mais velhos tiravam o sustento, evidenciando a origem camponesa: “[...] $\mathrm{Na}$ roça e a inchada na mão, feijão de corda, feijão de arranca, milho, melencia, abóbora[...]."

A vazante ${ }^{2}$ sempre foi o lugar do plantio. A memória dos ancestrais também está enraizada no modo de produzir materialmente a vida. Ainda hoje, no Mangal, coexistem espaços coletivos e espaços privados. Praticamente não existem cercas no espaço interno de Mangal, a não ser as que delimitam a antiga sede da fazenda, hoje sede da Associação Agro-Pastoril Quilombola de Mangal/Barro Vermelho, transformada em espaço coletivo. Nem mesmo na vazante, onde cada família cultiva seu "pedacinho”, são verificadas cercas.

A luta por essa terra é, sem dúvida, o elemento principal na construção da identidade quilombola dos moradores do Mangal. Em 1997, quando os moradores do Mangal iniciam o confronto com o Grupo Aliança, com o intuito de conquistar a posse da terra, eles eram simplesmente os negros do Mangal. Alguns deles, hoje lideranças, como 

CONTRIBUIÇÕES A PARTIR DA EXPERIÊNCIA DE UM QUILOMBO

$\overline{\text { Pereira (2005), Gomes (2005) e Santos, D. (2005) (os dois primeiros já não moravam }}$ na comunidade há algum tempo) buscavam junto a outros trabalhadores reivindicar um pedaço de terra de onde pudessem tirar o sustento. A luta inicial foi por um pedaço de terra na fazenda Vale Verde.

A negativa desses trabalhadores em inseri-los na luta e a provocação de que eles tinham terra, os forçaram a se organizarem para conquistar a fazenda. Até então conquistar a terra não tinha relação direta com tornar-se quilombola. O depoimento de Santos, D.(2005,) esclarece bem o caminho e as razões de tornar-se quilombola no Mangal:

Eu tinha um colega que falava nesse negoço de quilombo, mas ele não explicava o que é que significava quilombo, isso era nessa faixa aí de 80 , por aí. Aí, eu fiquei pensando assim... quilombola... Só que ele disse que o processo ia ser lento, mas vale a pena. Eu disse: Rapaz, sei não!. Lá na hora da reunião também num dei opinião, fiquei quieto! (SANTOS, D, 2005, informação oral).

Se para conquistar a terra era preciso tornar-se quilombola, isso seria feito, embora os moradores não tivessem noção alguma do que viria a ser quilombo. Até mesmo a primeira professora da comunidade confessa sua ignorância sobre o tema: “[...] pra lhe dizer a verdade, eu num sabia nem o que era quilombo" (TEIXEIRA, 2005, informação oral). Entretanto, considerando que as identidades são políticas e atendem uma demanda da contemporaneidade, podemos afirmar que a identidade quilombola do Mangal é legítima. Foram as demandas concretas do contexto social, econômico, político e cultural, no qual estavam inseridos, que impulsionaram esses indivíduos a assumir e a negar uma identidade. Não se pode perder de vista que durante muito tempo, em função de uma outra demanda, os moradores do mangal rejeitaram ser "mangazeiros" e, por conseguinte, toda a carga histórico-cultural que dava significado ao termo: 
[...] quando eu viajei daqui pra Juazeiro mais minha mãe de vapor (pausa), ela me falou: "Se alguém perguntar de onde você é, você fala que é de Paratinga, não é do Mangal não, você não é do Mangal" Puxa! E eu nunca perguntei a ela o porquê, mais depois que eu vim saber porque era. [...] Porque dizia que o Mangal era feiticeiro, o povo era, tá entendendo? (GOMES, 2005, informação oral).

Tornar-se quilombola a partir de uma necessidade imediata para fazer valer um direito constitucional de acesso à terra é absolutamente coerente com os preceitos da modernidade. Nada mais é do que uma estratégia que garantirá o cumprimento de uma promessa. Nesse sentido,

a política de realização praticada pelos descendentes dos escravos exige, como fez Delany, que a sociedade civil burguesa cumpra as promessas de sua própria retórica. [...] Ela é imanente à modernidade e um elemento de seu contradiscurso valioso demais para ser sistematicamente ignorado. (GILROY, 2001, p. 96).

A identidade quilombola utilizada como instrumento para a posse da terra vai possibilitar a esses indivíduos repensarem, inclusive, a negação da identidade "mangazeira" e ressignificá-la, e o que antes era motivo de vergonha é, hoje, razão suficiente para se orgulhar:

Eu não gostava não, quando eu saía daqui pra outro lugar, eu não falava que eu era daqui. Aí, oh! Hoje eu tenho o maior orgulho de falar: olha! Eu sou do Mangal, sou de lá do quilombo, a terra dos negros. Eu tenho mesmo, muito, eu tenho, mas antigamente eu não gostava não. (SANTOS, G., 2005, informação oral).

Isso só é possível porque no plano prático a identidade quilombola devolveu àqueles negros não apenas a terra a que tinham direito, mas com ela veio a dignidade, a liberdade e o trabalho, elementos suficientes para que eles pudessem se colocar em pé de igualdade com o seu entorno, agora dentro de um espaço que, embora sempre 
tenham sentido como seu, não podiam, até então, usufruir.

Os benefícios trazidos pela nova condição de proprietários da terra caminham lado a lado com o orgulho de ser quilombola. É inegável que essa nova condição trouxe a esses indivíduos direitos que possivelmente jamais usufruiriam fora desta. Sair de 700 metros de terra - sem direito à caça, à pesca e ao plantio - para oito mil hectares de terra dos quais são proprietários, é motivo suficiente para que se incorpore uma identidade. A narrativa de Gomes (2005) nos mostra de forma significativa a transformação por que passaram esses indivíduos após o seu reconhecimento. O tempo agora é o tempo da liberdade, da alegria, da fartura, da independência:

É. Então era uma coisa... é triste. Agora não, estou alegre [...] você chega na casa de um (pausa) trabalhador. Cheguei na casa de Barriga, ele me deu um copo de vitamina (pausa)[...] Tem um velhim que chega assim e fala: - "chegava aqui no Mangal procurava um ovo pra cumer e não achava", tá entendendo? [...] não tinha condições da gente criar nada, né?. Então, o exemplo é esse que a gente hoje é... consquistemos nosso espaço. Nós tem hoje, né. Se eu quiser é... oferecer um bode, um carneiro pra você, pra gente amanhã almoçar, eu tenho condições de dar. Graças a Deus nós tem a nossa criação, né. (GOMES, 2005, informação oral).

Os elementos considerados pelo Laudo Antropológico, exigido pela Fundação Palmares a fim de reconhecimento da comunidade como remanescente de quilombo, sempre existiram na comunidade tais: sua constituição baseada em laços de parentesco; atividade produtiva concentrada quase que exclusivamente na agricultura familiar de subsistência e a criação de animais de pequeno porte; a memória do cativeiro; as festividades que trazem em sua memória de práticas que remetem a uma origem africana, como a Roda de São Gonçalo e a Marujada; a convivência entre espaços coletivos e particulares e um sentido muito forte e solidário de comunalidade. Sendo assim, o que os fazem diferentes face à nova realidade?

Cadernos de Pós-graduação, São Paulo, v. 17, n. 2, p. 35-54, jul./dez. 2018. 
A questão é que a partir da luta pelo reconhecimento, esses elementos ganham sentido enquanto arma política na construção de uma identidade. Então, "aquilo que é assim porque sempre foi",

Esses indivíduos são quilombolas porque assim se identificam, e o prestígio social dessa nova identidade faz com que assim sejam reconhecidos em seu entorno. É na junção dessas duas identificações - uma interna, outra externa - que eles, "mangazeiros", negros feiticeiros sem menor prestígio, se descobrem quilombolas. Descobrem-se mesmo, porque sua identidade foi soterrada pelo racismo institucional que negou, historicamente, as condições para sua afirmação. Esse diferencial está expresso de forma clara na narrativa que se segue:

A maioria, tudo quer ser parente dos mangazeiro. A gente não tem nada, mas temo ao meno o nome, né? E aí, aí, antigamente não. Ah! Ninguém quer ir no Mangal, não. Ninguém quer misturar com os nêgo do Mangal não. Ficava separado... Se é do Mangal e chegasse em Paratinga, algumas pessoas...! Chegava na Lapa do mesmo jeito. E hoje não, tá tudo muderno [...]. (ASSIS, 2005, informação oral)

Neste processo, a inexistência de políticas educacionais voltadas para a valorização da população negra no processo formativo da sociedade brasileira e, ainda pior, a inferiorização e até a criminalização da cultura afro-brasileira, passando por um "esquecimento, voluntário", do negro no espaço escolar, contribuíram fortemente para a construção de estereótipos visando à desvalorização do negro em nossa sociedade, causando prejuízos não apenas para os negros - as maiores vítimas nesse processo, mas também para os não-negros que, em função do racismo, do preconceito explícito ou simbólico, por afirmação ou por negação, perderam a oportunidade de construir uma relação, diferente da existente, com seus negros pares. 


\section{CONCLUSÃO}

Creio que a discussão sobre identidade quilombola em Mangal pode dar uma contribuição significativa para pensarmos identidade como categoria política, motivada pelas demandas do contexto em que estão inseridos os sujeitos. Esse exercício nos convida a alargarmos nossas concepções acerca do tema, valorizando os vários modos de construção de quilombos e quilombolas presentes na história das comunidades negras rurais que, bem mais do que as populações negras urbanas, ficaram invisíveis aos olhos da sociedade envolvente, impossibilitadas de contar suas histórias que, certamente, contribuiriam para enriquecer o debate sobre a história dos negros escravizados e seus descendentes na diáspora.

As histórias e as lutas das comunidades quilombolas são tantas quantas são estas comunidades. Quilombos que têm suas histórias enraizadas no confronto direto com a sociedade senhorial; quilombos que construíram sua resistência na negociação cotidiana com a sociedade escravistas; quilombos que se organizaram no pós-escravidão e mantiveram vivas as histórias e tradições de seus ancestrais; quilombos do campo, da cidade, os quais praticam cotidianamente quilombagem ${ }^{3}$.

Entretanto, se considerarmos que estas formas diferenciadas de resistência contribuíram, ao seu modo, para minar a sociedade senhorial - que não se encerra com o fim da escravidão -, podemos admitir que aí também se praticou a “quilombagem”. As “Terras de Santo", a exemplo de Mangal, são o resultado de uma resistência negociada que transgride o princípio da sociedade escravagista na qual a prerrogativa da posse da terra era exclusividade do senhor. Nessa mesma direção, as diretrizes Curriculares $\mathrm{Na}$ cionais para a Educação Curricular Quilombola podem ser consideradas como uma expressão da quilombagem, visto que o fim do regime de escravidão não significou o 
fim do racismo e do preconceito racial no Brasil, outras lutas necessitaram e necessitam ser implementadas cotidianamente pela população negra em busca de equidade, igualdade e reconhecimento.

O esforço feito nesse trabalho foi no sentido de demonstrar que ampliar a compreensão do conceito de quilombo, com vistas a dar conta de articular um continuum entre as lutas contra a escravidão do Brasil, é necessária para atender, inclusive, as demandas por reparação social a que tem direito a população afro-brasileira. Os artigos 215 e 216 (Da Cultura), da Constituição Federal do Brasil, tornam legal o que já era de domínio popular ao reconhecer a contribuição dos negros na construção do patrimônio cultural da nação, além da garantia do exercício dos direitos culturais afro-brasileiros; entretanto, historicamente, os negros ficaram invisíveis na sociedade brasileira, apesar de sua maioria absoluta em termos quantitativos na população do país.

As Diretrizes Curriculares Nacionais para a Educação Escolar Quilombola na Educação Básica são mais um instrumento na luta contra o racismo, contra o preconceito, bem como por reparação histórica e social. Sua implementação é instrumento potencializador na construção de uma história diferente para a população brasileira e na construção de uma outra educação nos quilombos. Mas,para tanto, faz-se necessário a instrumentalização didático pedagógica de suas escolas, investir na formação dos professores que atuam nessas comunidades e, principalmente, criar as condições para a formação de quadros qualificados que estejam enraizados nos quilombos.

\section{REFERÊNCIAS}

ASSIS, Francisco de. (Chicão). Depoimento [janeiro, 2005]. Entrevistadora: Sandra Nivia Soares de Oliveira UEFS, 2005. Cassete sonor. Entrevista concedida à pesquisadora Sandra Nivia Soares de Oliveira. Sítio do Mato - Bahia, 2005.

BRASIL. Constituição (1988). Constituição da República Federativa do Brasil. Brasília, DF: 
Senado Federal: Centro Gráfico, 1988. 292 p.. Disponível em: < http://www.planalto.gov.br/ccivil 03/Constituicao/Constituicao.htm>. Acesso em: 25 jun. de 2015.

BRASIL, Ministério da Educação, Conselho Nacional de Educação, Câmara de Educação Básica.Rresolução no 8, de 20 de novembro de 2012. Define Diretrizes Curriculares Nacionais para a Educação Escolar Quilombola na Educação Básica.. Publicação no DOU n. ${ }^{\circ} 224$, de 21.11.2012, Seção 1, página 26/30. Disponível em:

$<$ http://www.seppir.gov.br/portal-antigo/arquivos-pdf/diretrizes-curriculares $>$. Acesso em: 25 jun. de 2015.

CASTELLS, Manuel. O poder da Identidade: (a era da informação: economia, sociedade e cultura). São Paulo: Paz e Terra, 1999.

GILROY, Paul. O Atlântico Negro - Modernidade e Dupla Consciência. Rio de Janeiro, Editora 34/UCAM — Centro de Estudos Afro-Asiáticos, 2001.

GIRAUDO, José Eduardo Fernandes. Poética da Memória: uma leitura em Toni Morrison. Porto Alegre: ed. Universidade/UFRS, 1997.

GOMES, Carlos Alberto dos Santos. (Carlinhos). Depoimento [janeiro, 2005]. Entrevistadora: Sandra Nivia Soares de Oliveira UEFS, 2005. Cassete sonor. Entrevista concedida à pesquisadora Sandra Nivia Soares de Oliveira. Sítio do Mato - Bahia, 2005.

LARA, Silvia Hunold. Do singular ao plural: Palmares, capitães-do-mato e o governo dos escravos. In: REIS; GOMES (Org.). Liberdade por um fio: história dos quilombos no Brasil. São Paulo: Companhia das Letras, 1996.

MATTOS, Wilson Roberto de. Valores Civilizatórios Afro-Brasileiros na Elaboração de

Currículos Escolares - Ensaiando Pressupostos. In: RAMOS, Marise Nogueira, ADÃO, Jorge Manoel, BARROS, Maria Graciete Nascimento (Org.). Diversidade na educação: reflexões e experiências. Brasília: Secretaria de Educação Média e Tecnológica, 2003.

MOURA, Clóvis. A quilombagem como expressão de protesto radical, In: (Org.). Os Quilombos na dinâmica social do Brasil. Maceió: EDUFAL, 2001. 
MOURA, Glória. Os quilombos contemporâneos e a educação. In: Revista Humanidades. UnB Editora: Brasília: n. 47. p. 999-116, novembro, 1999.

PEREIRA, Egidio Gomes. (Senhorzinho). Depoimento [ janeiro, 2005]. Entrevistadora: Sandra Nivia Soares de Oliveira UEFS, 2005. Cassete sonor. Entrevista concedida à pesquisadora Sandra Nivia Soares de Oliveira. Sítio do Mato - Bahia, 2005.

SANTOS, Deraldo dos. (Caboje). Depoimento [janeiro, 2005]. Entrevistadora: Sandra Nivia Soares de Oliveira UEFS, 2005. Cassete sonor. Entrevista concedida à pesquisadora Sandra Nivia Soares de Oliveira. Sítio do Mato - Bahia, 2005.

SANTOS, Guilhermina Farias dos. Depoimento [ janeiro, 2005]. Entrevistadora: Sandra Nivia Soares de Oliveira UEFS, 2005. Cassete sonor. Entrevista concedida à pesquisadora Sandra Nivia Soares de Oliveira. Sítio do Mato - Bahia, 2005.

SANTOS, Isauro Lobo dos. Depoimento [ janeiro, 2005]. Entrevistadora: Sandra Nivia Soares de Oliveira UEFS, 2005. Cassete sonor. Entrevista concedida à pesquisadora Sandra Nivia Soares de Oliveira. Sítio do Mato - Bahia, 2005.

SODRÉ, Muniz. Claros e escuros: identidade, povo e mídia no Brasil. Rio de Janeiro: Vozes, 1999.

SOUZA, Clara Carvalho de. Depoimento [ janeiro, 2005]. Entrevistadora: Sandra Nivia Soares de Oliveira UEFS, 2005. Cassete sonor. Entrevista concedida à pesquisadora Sandra Nivia Soares de Oliveira. Sítio do Mato - Bahia, 2005.

SOUZA, Martinho Gomes de. Depoimento [janeiro, 2005]. Entrevistadora: Sandra Nivia Soares de Oliveira UEFS, 2005. Cassete sonor. Entrevista concedida à pesquisadora Sandra Nivia Soares de Oliveira. Sítio do Mato - Bahia, 2005.

TEIXEIRA, Cremilda de. Depoimento [janeiro, 2005]. Entrevistadora: Sandra Nivia Soares de Oliveira UEFS, 2005. Cassete sonor. Entrevista concedida à pesquisadora Sandra Nivia Soares de Oliveira. Sítio do Mato - Bahia, 2005.

VÉRAN, Jean-François. Rio das Rãs: Memória de uma "Comunidade Remanescente de quilombo" In: Revista Afro-Àsia, n. 23. Salvador: CEAO/EDUFBA, 1999.

\section{NOTAS:}


1 Terras de Santo ou Terras de Santíssima, que indicam uma territorialidade derivada da propriedade detida em mãos de ordens religiosas, da doação de terras para santos e do recebimento de terras em troca de serviços religiosos prestados a senhores de escravos por negros e negras, sacerdotes ou sacerdotisas de cultos religiosos afro-brasileiros.

2 Área fértil às margens do Rio São Francisco onde os moradores fazem sua roça.

${ }^{3}$ É um processo social contínuo de protesto que se desenvolve dentro da estrutura escravista, solapando-a histórica, econômica, étnica, e socialmente a partir de seu centro, isto é , a produção [...] um continuum que só termina com a abolição do sistema escravista colonial." (MOURA, C., 2001, p. 112).

recebido em 4 mar. 2018 / aprovado em 31 jul. 2018

\section{Para referenciar este texto:}

OLIVEIRA, S. N. S. Identidade quilombola e educação escolar quilombola: contribuições a partir da experiência de um quilombo. Cadernos de Pós-graduação, São Paulo, v. 17, n.2, p. 35-54, jul./dez. 2018. Disponível em: <https://doi.org/10.5585/cpg.v17n2.8429>. 